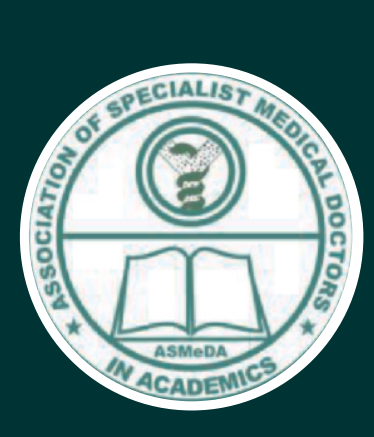

ISSN:Print: 2811-1672

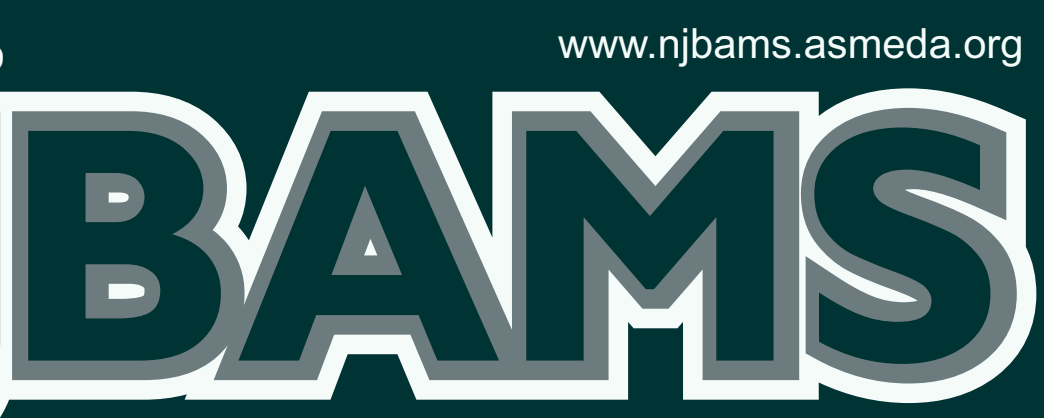

Nigerian Journal of Basic and Applied Medical Sciences

An official publication of the National

ASSOCIATION OF SPECIALIST MEDICAL DOCTORS IN

ACADEMICS (ASMeDA aka MEDSABAMS) 


\title{
Eucalyptus globulus Methanol Leaf Extract Improves Glycosylated Hemoglobin, Lipid Profile Levels and Haematological Sub-inflammatory Biomarkers in Streptozotocin-induced Diabetic Rats
}

\author{
Ajilore B.S. ${ }^{*}$, Fatoki J.O. ${ }^{1}$, Abayomi T.A. ${ }^{2}$ \\ Department of Medical Biochemistry, College of Health Sciences, Osun State University, Osogbo, Nigeria. \\ Department of Anatomy, College of Health Sciences, Osun State University, Osogbo, Nigeria.
}

\begin{abstract}
Background: Eucalyptus leaf is used traditionally to treat a lot of diseases, but little is known about its use in the management of diabetes mellitus (DM) and its complications.

Objectives: Antidiabetic property of Eucalyptus globulus leaf extract (EGLEX) was assessed on recent Makers of therapeutic response and diabetic disease progression in streptozotocin-induced diabetic rats.

Methods: Eucalyptus globullus leaf powder $(200 \mathrm{~g})$ was extracted with methanol using standard procedure. Hyperglycemia was induced in Wistar rats with single intravenous dose of $50 \mathrm{mg} / \mathrm{kg} / \mathrm{bwt}$ streptozotocin. The rats were divided into five groups $(\mathrm{n}=5)$ : Anormal control, B- diabetic control, C, D and E were diabetic rats treated with Eucalyptus globullus leaf extract (EGLEX), metformin and insulin respectively for four weeks. Samples were collected for biochemical and hematological studies. Data obtained were analysed using One Way Analysis of Variance at $<0.05$ significance level.
\end{abstract}

Results and Conclusion: The results showed significant $(\mathrm{p}<0.05)$ blood glucose reduction of $68 \%, 51 \%$ and $68 \%$, and weight gain of $17 \%, 18 \%$ and $11 \%$ in rats treated with EGLEX, metformin and insulin respectively. HBA1c level was significantly $(\mathrm{p}<0.05)$ raised $(9.30 \%)$ in diabeticuntreated rats when compared with normal control (3.77\%), EGLEX $(4.24 \%)$, metformin $(4.94 \%)$ and insulin $(5.33 \%)$ groups. The deranged lipid profile indices, malondialdehyde and reduced glutathione levels, superoxide dismutase activity, platelet count, $\%$ neutrophil and $\%$ lymphocyte were normalized in diabetic rats treated with EGLEX when compared with the values in diabetic untreated rats. The findings concluded that EGLEX possesses antidiabetic property and improves biomarkers of diabetic disease progression.

Keywords: Eucalyptus globullus leaf, glycosylated haemoglobin, lipid profile indices, hematological indices, diabetic complications.

Corresponding Author: Ajilore B.S. (M.B.Ch.B, PhD)

Address: Department of Medical Biochemistry, College of Health Sciences,

Osun State University, PMB 4494, Osogbo, Osun State, Nigeria.

E-mail: doctorajibam@yahoo.com

Phone: +2347033985727

\section{INTRODUCTION}

The use of herbal medicines in the treatment of various diseases has witnessed a great surge globally. Eucalyptus globulus, also known as Tasmanian blue gum, is an evergreen broadleaf tree native to Tasmania and Southern Victoria of South-eastern Australia (1).

E. globulus is a specie that is widely introduced overseas (2) and has been established in many countries including Nigeria (3). In Nigeria, it is called 'kafur' in the northern part of the country while southeasterners call it 'nkwu-ishi'. Eucalyptus plant is used traditionally for treating a lot of diseases. The essential oil from the leaf is generally being used to treat diseases of respiratory tract system. Other medicinal uses are antimicrobial, antifungal, antiviral, antiinflammatory, analgesic, insect repellent and antioxidant agents. The plant is not known by herb sellers, herbalists and traditional medicine practitioners in Nigeria in the management of diabetes. Few studies also reported the antidiabetic property of the study plant. In a study, incorporation of aqueous extract of Eucalyptus leaf in the diet and drinking water reduced the hyperglycemia and associated weight loss of steptozotocin-treated mice. $(4,5)$.

Diabetes mellitus (DM) is a multisystemic metabolic disease characterized by defective carbohydrate, protein and fat metabolism resulting from relative or absolute deficiency of insulin and/or insulin resistance (6). Persistent exposure to hyperglycemia, poor glycemic control and dyslipidemia are risk factors for the progression of DM (7) and development of complications. Percentage glycosylated hemoglobin (HBA1c), cholesterol ratio (TC/HDL-C), neutrophil/lymphocyte ratio (NLR), platelet/lymphocyte ratio (PLR) are simple inexpensive recent biomarkers to determine diabetic complications $(8,9)$. Therefore, this research aimed at investigating antidiabetic effects of Eucalyptus globulus leaf extract on these biomarkers of diabetic disease progression.

Cite this article as: Ajilore B.S., Fatoki J.O., Abayomi T.A. Eucalyptus globulus Methano Leaf Extract Improves Glycosylated Hemoglobin, Lipid Profile Levels and Haematological Sub-inflammatory Biomarkers in Streptozotocin-induced Diabetic Rats Nig. J. Basic \& Applied Med. Sci. 2021;1(1);14-18.

\section{Methodology}

Reagents and chemicals

The following reagents and chemicals were used for the study: Normal saline, Sodium citrate, citric acid, metformin, insulin $\left(\right.$ Humulin $^{\mathrm{R}}$ ), Mono-potassium phosphate, Di-potassium phosphate, sodium hydroxide, hydrogen peroxide, hydrochloric acid, trichloroacetic acid, Turke's solution, Gential violet, ammonium oxalate, Hayem's fluid were purchased from Sigma chemical company, St. Lious, Mo, U.S.A., and British Drug House (BDH) chemical Ltd., Poole, England. $\mathrm{HbA1}_{\mathrm{C}}$ kit was pyurchased from INTECO chemical company while total cholesterol kit, HDL-cholesterol kit and triglyceride kit were obtained from Randox Laboratories Ltd., Crumlin, Co. Antrim, U.K. All reagents and chemicals used were of analytical grade.

\section{Collection and Preparation of Eucalyptus globullus Leaf \\ Experimental Animals}

Forty male albino rats were used for the study. The rats were bought from the college animal house where they were kept in well ventilated cages. The cages were lined with wood husks, renewed every 24 hours under a 12:12 hour light/dark cycle at room temperature. The rats had free access to water and commercial standard pellets and were acclimatized for two weeks. Experimental animals were used according to the protocol of the Department of Biochemistry, LAUTECH Ethics Committee Guidelines on the use of vertebrate animals for experiments, and this was in conformity with the National Research Council guide for the care and use of laboratory animals (10). Hyperglycemia was induced with a single intravenous dose of $50 \mathrm{mg}$ per $\mathrm{kg}$ body weight streptozotocin in twenty-five rats, and those with blood glucose levels $>10 \mathrm{mmol} / \mathrm{L}$ after 72 hours was considered diabetic and recruited for the study. The rats were randomly divided into five groups $(\mathrm{n}=5)$ as follows:

Group 1: Normal control.

Group 2: Diabetic untreated.

Group 3: Diabetic treated with $200 \mathrm{mg} / \mathrm{kg}$ body weight EGLEX 
Group 4: Diabetic treated orally with $7 \mathrm{mg} / \mathrm{kg}$ body weight Metformin $(9,11)$.

Group 5: Diabetic rats treated subcutaneous with $0.4 \mathrm{IU} / \mathrm{kg}$ body weight $\operatorname{Humulin}^{\mathrm{R}}(9,11)$.

Treatment was done once daily for four weeks. The weights and blood sugar of each rat was observed before induction, after induction of diabetes, and after treatment. Ocular puncture was used to collect blood sample (following overnight fasting) before sacrifice, prepared and used for biochemical studies. Following sacrifice, tissue was harvested, prepared and used for biochemical and histological studies. Tissue for histology was preserved in formalin.

\section{Extraction of Eucalyptus globullus Leaf}

Eucalyptus globullus leaf powder (200 g) was subjected to cold maceration with frequent agitation in 2 liters of $100 \%$ methanol for 72 hours at room temperature (11). The extract was filtered using a muslin cloth and filtrate concentrated using rotary evaporator. Eucalyptus globullus leaf extract (EGLEX) was stored in the fridge until used.

\section{Acute toxicity test}

Eucalyptus globullus leaf extract (EGLEX) was subjected to acute toxicity test using Organization for Economic Cooperation and Development (OECD) guidelines (number 423), starting from a fixed dose of $50 \mathrm{mg} / \mathrm{kg}$ body weight. Nine rats of the same age group and weight $(\mathrm{n}=3)$ were dosed up to $2000 \mathrm{mg} / \mathrm{kg}$ body weight through oral administration. The animals were observed for signs of toxicity for the first 1 hour, hourly for 4 hours and finally every 24 hours for 14 days. Ten percent of $\operatorname{LD}_{50}(2000 \mathrm{mg}$ $/ \mathrm{kg}$ ) was safe dose used to treat the animals.

\section{Preparation of Blood and Tissue Samples}

Blood sample was collected into plain and EDTA labelled bottles. Sample in plain bottle was allowed to clot, and then and centrifuged at $3000 \mathrm{rpm}$ for $10 \mathrm{~min}$. The clear serum separated was kept in freezer till assay. Whole blood in EDTA bottle was mixed immediately with respective diluting fluids and used to assay hematological parameters.

Brain, liver and kidney tissues harvested from each rat were weighed and homogenized in potassium phosphate buffer (tissue /total buffer (w/v) is 1:10). The supernatant obtained after the homogenate was centrifuged at $6000 \mathrm{rpm}$ for $5 \mathrm{~min}$ at $4{ }^{\circ} \mathrm{C}$ using refrigerated centrifuge was kept in freezer till assay.

\section{Assay for glycosylated hemoglobin (HbA1c)}

HBA1c level in blood was determined according to ion exchange resin method as described by Nathan et al (12) using Spectrum diagnostic kit for glycosylated hemoglobin.

\section{Assay for Haematological Indices}

Total leukocyte count (TLC) and differentials, red cell count and platelet count were determined according to the method of Ramnik (13).

\section{Assay for Lipid Profile Parameters}

Total cholesterol was determined as described by Tonks (14), high density (HDL) cholesterol by Assmanna et al. (15) and triglyceride by enzymatic hydrolysis with lipase (16) using Randox diagnostic kits.

\author{
LDL Cholesterol $=$ \\ Total Cholesterol Triglyceride - HDL Cholesertol
}

\section{Assay for Lipid peroxidation (LPO) and Reduced Glutathione (GSH) Levels, and Superoxide dismutase (SOD) Activity}

The extent of LPO in the brain, kidney and liver was determined by estimating the release of thiobarbituric reactive substances as described by Ottolenghi (17) and expressed as nanomolar of malondialdehyde (MDA)/g tissue. GSH level was determined by the method of Sapakal et al. (18), while SOD activity was estimated using the method of McCord and Fridovich (19). Total protein level in the tissues was determined as described by Gornal et al. (20) using the Randox diagnostic kit.

\section{Statistical Analysis}

Data obtained were analysed using One Way Analysis of Variance (ANOVA) of statistical package for social sciences (SPSS version 25.0). Levene statistic was used to test homogeneity of variance while Tukey was used in determining multiple comparisons and homogenous subsets. Results considered to be statistically significant at less than 0.05 .

\section{Results}

\section{Acute Toxicity}

The LD50 for EGLEX was at $2000 \mathrm{mg} / \mathrm{kg}$ body weight. The safe dose of $200 \mathrm{mg} / \mathrm{kg}$ bwt (which is the $10 \%$ of $2000 \mathrm{mg} / \mathrm{kg}$ bwt) was used to treat the diabetic rats (9).

\section{Average Blood Glucose and Body Weight in Control, Dia- betic and Treated Rats}

Intravenous administration of $50 \mathrm{mg} / \mathrm{kg}$ body weight streptozotocin to rats significantly $(\mathrm{p}<0.05)$ increased blood glucose level after 72 hours when compared with normal control rats (Table 1). Treatment of diabetic rats for 4 weeks with EGLEX, metformin and insulin caused significant $(\mathrm{p}<0.05)$ reduction in blood glucose by $68 \%, 51 \%$ and $68 \%$ respectively when compared with diabetic untreated group. Also, the significant $(\mathrm{p}<0.05)$ weight loss caused by induction of hyperglycemia using streptozotocin (Table 2) was significantly $(\mathrm{p}<0.05)$ reverted following treatments with EGLEX (17\%), metformin $(18 \%)$ and insulin $(11 \%)$.

Table 1. Average Blood Glucose (mg/dl) of Rats in Control and Treatment Groups

\begin{tabular}{lllll}
\hline Treatment Group & Before Induction & After Induction & After Treatment & $\begin{array}{l}\text { Approx. \% Blood Glucose } \\
\text { Change }\end{array}$ \\
\hline Normal Control & $72.33 \pm 6.81$ a & $78.33 \pm 6.50 \mathrm{a}$ & $82.00 \pm 5.29 \mathrm{a}$ & $5 \%$ \\
Diabetic Control & $60.67 \pm 5.13 \mathrm{a}$ & $338.67 \pm 35.44 \mathrm{~b}$ & $393.33 \pm 29.37 \mathrm{c}$ & $16 \%$ \\
$\begin{array}{l}\text { Diabetic }+250 \mathrm{mg} / \mathrm{kg} \\
\text { Methanol Extract }\end{array}$ & $97.33 \pm 6.81 \mathrm{~b}$ & $332.33 \pm 92.23 \mathrm{~b}$ & $104.00 \pm 14.42 \mathrm{ab}$ & $-69 \%$ \\
$\begin{array}{l}\text { Diabetic }+7 \mathrm{mg} / \mathrm{kg} \\
\text { Metformin }\end{array}$ & $56.67 \pm 7.64 \mathrm{a}$ & $328.33 \pm 46.92 \mathrm{~b}$ & $159.57 \pm 18.58 \mathrm{~b}$ & $-51 \%$ \\
$\begin{array}{l}\text { Diabetic }+0.4 \text { unit } / \mathrm{kg} \\
\text { Humulin R }\end{array}$ & $76.00 \pm 22.72 \mathrm{ab}$ & $320.67 \pm 75.66 \mathrm{~b}$ & $102.67 \pm 12.58 \mathrm{ab}$ & $-68 \%$ \\
\hline
\end{tabular}

Results are expressed in Mean \pm S.D $(\mathrm{n}=5) . \mathrm{a}, \mathrm{b}$ and $\mathrm{ab}$ are significan homogenous subsets of mean. Mean with different Duncan superscripts between the treatment groups are statistically significant at $\mathrm{P}<0.05$ 
Table 2. Average Body Weight (g) of Rats in Control and Treatment Groups

\begin{tabular}{|c|c|c|c|c|c|}
\hline Treatment Group & Before Induction & After Induction & After Treatment & $\begin{array}{l}\text { Approx. \% Body Weight } \\
\text { Change }\end{array}$ & \\
\hline Normal Control & $175.00 \pm 21.28^{a}$ & $190.33 \pm 23.39 \mathrm{~b}$ & $217.00 \pm 28.54^{c}$ & $14 \%$ & \\
\hline Diabetic Control & $169.33 \pm 22.81^{\mathrm{a}}$ & $149.00 \pm 11.12^{\mathrm{a}}$ & $128.67 \pm 8.93^{a}$ & $-13 \%$ & \\
\hline $\begin{array}{l}\text { Diabetic }+200 \mathrm{mg} / \mathrm{kg} \\
\text { Methanol Extract }\end{array}$ & $166.67 \pm 15.89^{\mathrm{a}}$ & $148.33 \pm 11.08^{\mathrm{a}}$ & $173.67 \pm 20.69^{b}$ & $17 \%$ & \\
\hline Diabetic $+7 \mathrm{mg} / \mathrm{kg}$ & $164.67 \pm 27.30^{\mathrm{a}}$ & $145.00 \pm 9.53^{\mathrm{a}}$ & $171.67 \pm 19.71^{b}$ & $18 \%$ & \\
\hline $\begin{array}{l}\text { Diabetic }+0.4 \text { unit } / \mathrm{kg} \\
\text { Humulin }^{\mathrm{R}}\end{array}$ & $159.67 \pm 12.03^{a}$ & $146.33 \pm 10.26^{a}$ & $162.33 \pm 24.02^{\mathrm{b}}$ & $11 \%$ & $\begin{array}{l}\text { Results are expressed in Mean } \pm \text { S.D } \\
(\mathrm{n}=5) \text {. a, } \mathrm{b} \text { and ab are significant } \\
\text { homogenous subsets of mean. } \\
\text { Means with different Duncan } \\
\text { superscripts between the treatment } \\
\text { groups are statistically significant at } \\
P<0.05\end{array}$ \\
\hline
\end{tabular}

Percentage Glycosylated Hemoglobin (HBA1c) in Control, Diabetic and Treatment Groups

Hyperglycemia induced by streptozotocin administration significantly $(\mathrm{p}<0.05)$ raised the percentage of haemoglobin glycosylation in diabetic group $(9.30 \pm 2.10)$ while treatments with EGLEX $(4.24 \pm$ $0.61)$, metformin $(4.94 \pm 0.13)$ and insulin $(5.33 \pm 0.55)$ significantly $(p<0.05)$ reduced percentage glycosylated haemoglobin when compared with the value in normal control group $(3.77 \pm 0.39)$ (Figure 1).

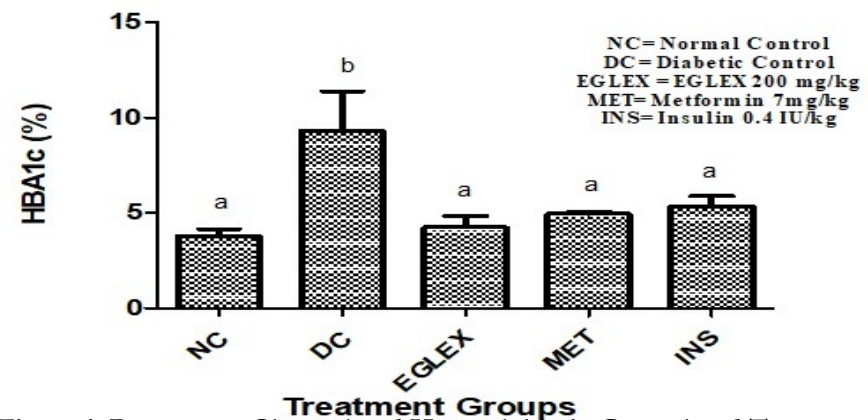

Figure 1. Percentage Glycosylated Hemoglobin in Control and Treatmen Groups. Values are expressed as mean \pm S.D $(n=5)$. Tukey superscripts a and b are significant homogenous subsets of means between groups. Parameters with different superscripts between the treatment groups are statistically significant at $\mathrm{p}<0.05$

Hematological Parameters in Control and Treatment Groups Packed cell volume $(\mathrm{PCV})$ was significant $(\mathrm{p}<0.05)$ reduced in all the diabetic rats but marked decrease was observed in diabetic untreated group (Figure 2). In diabetic untreated rats, there was significant $(\mathrm{p}<0.05)$ increase in platelet count and percentage lymphocyte with a significant $(\mathrm{p}<0.05)$ decrease in total WBC and percentage neutrophil when compared with the values in normal control and treated rats.

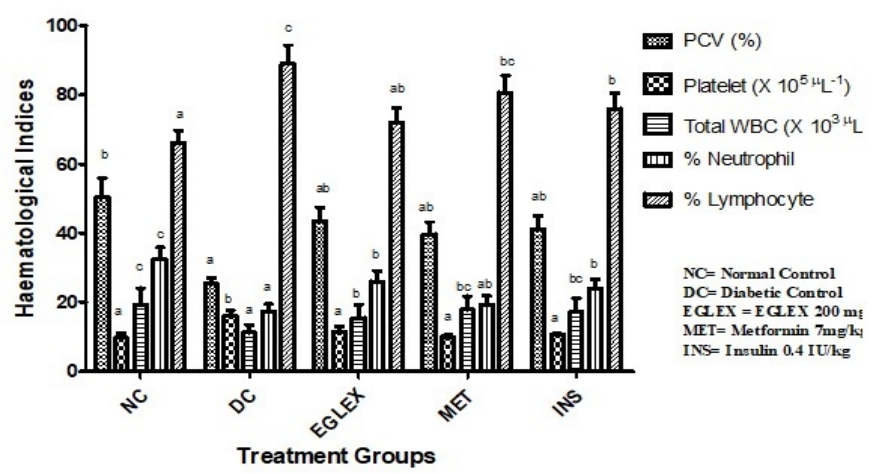

Figure 2. Hematological Indices in Control and Treatment Groups. Values are expressed as mean $+S . D(n=5)$. Tukey superscripts $a, b, a b$, bc and $c$ are significant homogenous subsets of means between groups. Parameter with different superscripts between the treatment groups are statistically significant at $\mathrm{p}<0.05$.
When the levels of HBA1c was correlated with neutrophil/lymphocyte ratio (NLR) and platelet/lymphocyte ratio (PLR), no significant correlation was observed in the normal control, EGLEX, metformin and insulin groups (Figure 3). In diabetic untreated group, perfect positive correlation was observed between HBA1c and PLR while the correlation between HBA1c and NLR was negative and weak.

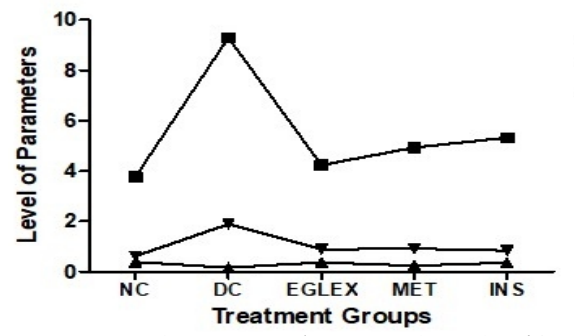

- HBA1c

$\mp$ NLR

$\rightarrow$ PLR

NC $=$ Normal Control DCE Diabetic Control
ECLEX $=$ EGLEX $200 \mathrm{mg} / \mathrm{k}$ MET $=$ Metformin $7 \mathrm{mg} / \mathrm{kg}$

Figure 3. Correlation matrix between Glycosylated hemoglobin (HBA1c), Neutrophil/Lymphocyte Ratio (NLR), and Platelet/Lymphocyte Ratio (PLR)

\section{Serum Lipid Profile in Control and Treatment Groups}

Total cholesterol (TC) and low-density lipoprotein cholesterol level (LDL-C) levels were significantly $(\mathrm{p}<0.05)$ raised in diabetic untreated rats with a significant $(\mathrm{p}<0.05)$ reduction in the levels of triglyceride and high-density lipoprotein cholesterol when compared with the values in normal control and treated rats (Figure 4).

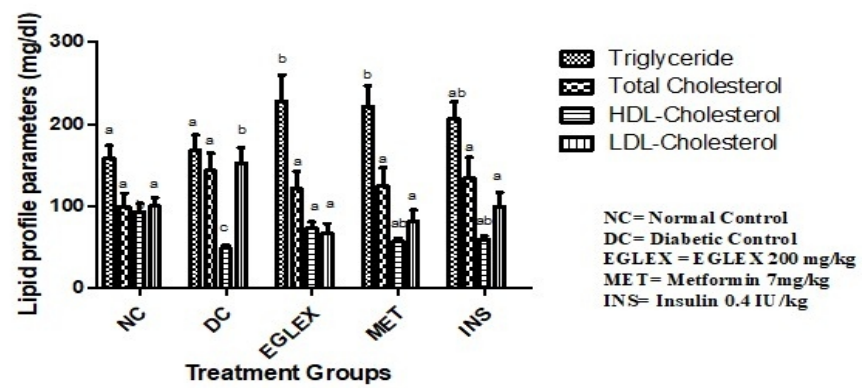

Figure 4. Lipid Profile in Control and Treatment Groups. Values are expressed as mean \pm S.D $(n=5)$. Tukey superscripts $a, b$, ab, and $c$ are significant homogenous subsets of means between groups. Parameter with different superscripts between the treatment groups are statistically significant at $\mathrm{p}<0.05$.

There was no relationship between glycosylated haemoglobin (HBA1c) and cholesterol ratio (TC/HDL-C) in normal control rats (Figure 5). In diabetic untreated rats, a perfect positive correlation was observed between HBA1c and TC/HDL-C when compared with the weak positive relationship seen in the treated rats.

Thiobarbituric Acid Reactive Substances, Reduced Glutathione Levels and Superoxide Dismutase Activity in the Control and Treatment Groups

The extent of lipid peroxidation, reduced glutathione level and superoxide dismutase activity were shown in figures 6,7 and 8 respectively. 


\section{Discussion}

Eucalyptus globulus leaf has shown promising potential in its efficacy to manage some diseases but little is known about its use in the management of diabetes mellitus (DM). This study investigated antihyperglycemic potential of Eucalyptus globulus leaf extract (EGLEX) on some biomarkers of diabetic prognosis and disease progression.

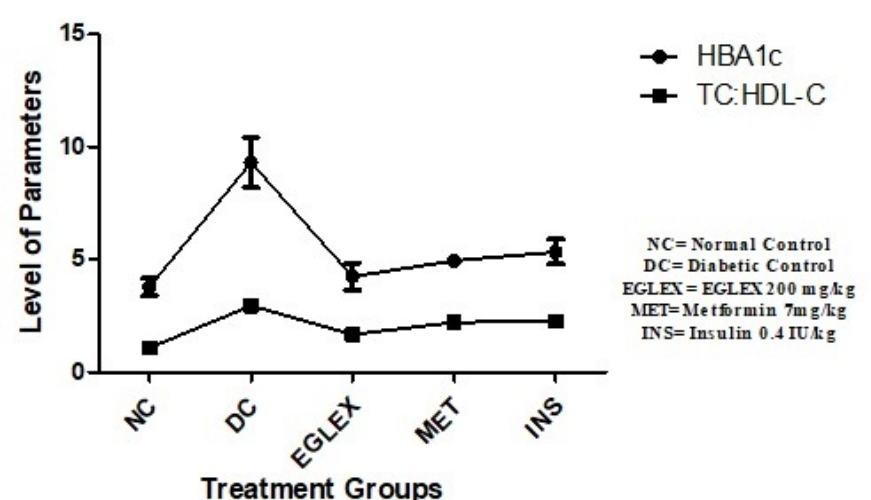

Figure 5. Correlation matrix between Glycosylated hemoglobin (HBA1c), and Cholesterol Ratio (TC/HDL-C)

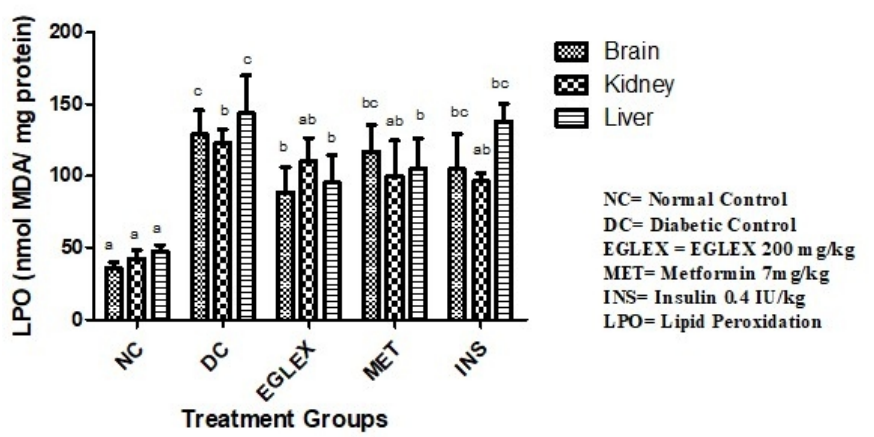

Figure 6. Level of Lipid Peroxidation in Control and Treatment Groups Values are expressed as mean \pm S.D $(n=5)$. Tukey superscripts $a, b$, ab bc and $c$ are significant homogenous subsets of means between groups. Parameter with different superscripts between the treatment groups are statistically significant at $\mathrm{p}<0.05$.

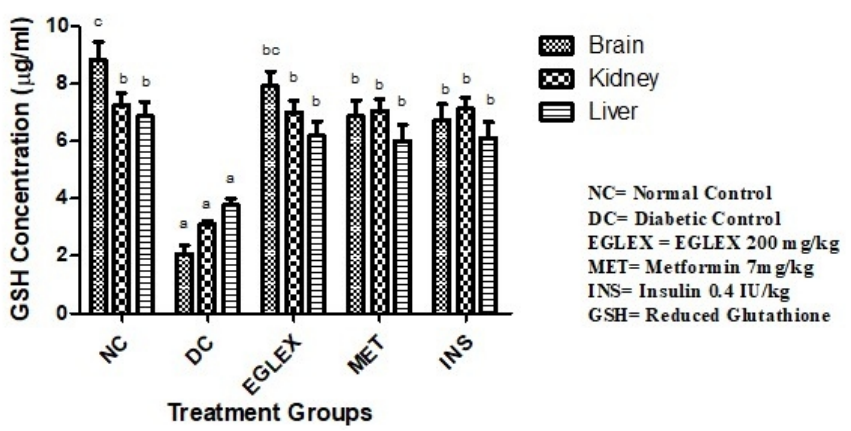

Figure 7. Reduced Glutathione Level in Control and Treatment Groups. Values are expressed as mean \pm S.D $(n=5)$. Tukey superscripts $a$, b, and ab are significant homogenous subsets of means between groups. Parameter with different superscripts between the treatment groups are statistically significant at $\mathrm{p}<0.05$.

The risk factors for the progression of DM are longer duration of hyperglycemia and poor glycemic control $(21,22)$. Administration of EGLEX to diabetic rats reduced blood glucose level and improved the body weight of the diabetic rats. Morphinan-4,5 epoxy3,6diol,6[7nitrobenzofurazan-4-yl] amino- in EGLEX is responsible for its antidiabetic activity (23). A significant reduction in the body weight of rats following induction with streptozotocin (STZ) was in support of previous studies $(24,25)$.
Persistent hyperglycemia in diabetic untreated rats was responsible for increase in percentage HBA1c observed in that group (9). HBA1c level is not only of diagnostic important but it is also used for the assessment of diabetes mellitus during the management (26). HBA1c could be used to explain the significant reduction in packed

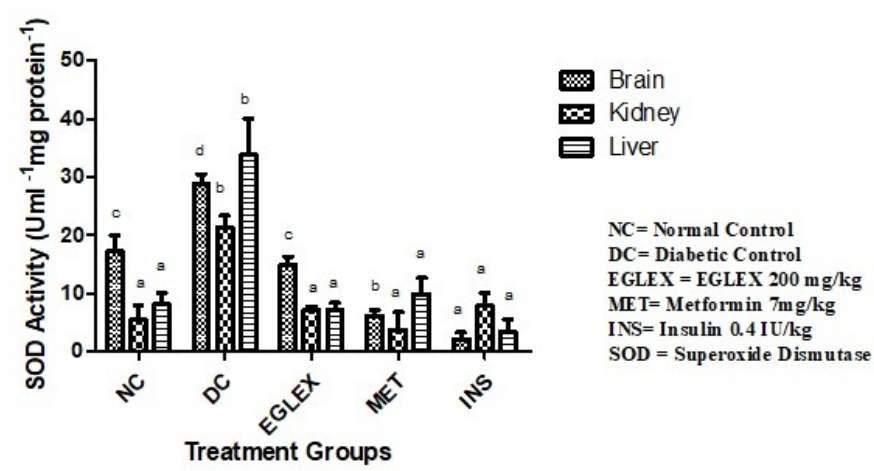

Figure 8. Superoxide dismutase Activity in Control and Treatment Groups. Values are expressed as mean \pm S.D $(n=5)$. Tukey superscripts a, b, c, and d are significant homogenous subsets of means between groups. Parameter with different superscripts between the treatment groups are statistically significant at $\mathrm{p}<0.05$.

cell volume (PCV) of red blood cell in the same group. Hyperglycemia leads to attachment of glycosylated end-product to hemo globion of red blood cells. If it coats the adhesion molecules of inflammatory cells, there could be immune-compromised state (26). The reduction in the level of HBA1c in rats treated with EGLEX, metformin and insulin was due to their anti-hyperglycemic property and hence near-normal PCV seen in those groups. Platelet count and percentage lymphocytes were also raised in diabetic rats while total white blood cell (WBC) count and percentage neutrophil were reduced when compared to the values observed in the treated groups. This is in support of recent studies that total WBC and \% neutrophil decrease in type 1 diabetes while percentage lymphocyte increases $(9,27)$. Inflammation plays a central role in the development and progression of diabetes and of its complications. The neutrophillymphocyte ratio (NLR) and plateletlymphocyte ratio (PLR) are indicators of subclinical inflammation $(9,28)$. Increased platelet activity plays a role in the development of micro- and macro-vascular complications in diabetes (29,30). Persistent hyperglycemia increased PLR and reduced NLR in diabetic rats. The relationship between HBA1c and PLR in diabetic rats is perfectly positive but negatively (though weak) associated with NLR. Treatment of diabetic rats with EGLEX normalized the deranged inflammatory markers. Recent clinical studies confirm that deranged PLR and NLR are associated with diabetic macrovascular and microvascular complications $(31,32)$. Neutrophil lymphocyte ratio (NLR), platelet lymphocyte ratio (PLR) and platelet indices are simple and cost-effective blood inflammatory markers (unlike the expensive non-routine interleukins assays) which are easily determined and have been found to be associated with a lot of pathological states (8).

Induced diabetes resulted in significant increase in the levels of total cholesterol, low density lipoprotein cholesterol (LDL-C), and cholesterol ratio (TC/HDL-C) in diabetic untreated rats while administration of EGLEX, metformin and insulin to diabetic rats normalized lipid profile indices. Reduction in the level total cholesterol in diabetic rats administered EGLEX is due to hypocholesterolemic property of 1 -Heptatriacotanol present in the plant (21). Higher cholesterol ratio means higher risk of heart disease (33). HbA1c is also a useful predictor of lipid profile and monitoring of glycemic control using HbA1c could be beneficial 
in identifying diabetic patients who are at a greater risk of cardiovascular complications (34). The perfect positive correlation observed between HBA1c and TC/HDL-C in this study supports previous studies $(35,36)$.

Persistent hyperglycemia induces oxidative stress which generates free radicals which causes an irreversible oxidative modification of lipids, proteins, DNA and carbohydrates $(25,37)$. GSH acting as the first line defense mechanism, there is oxidation of its thiol group, reduction in its tissue level with resulting in accumulation of oxidative stress products, such as advanced glycation endproducts, protein oxidation products and lipid peroxidation. The significant decrease in the level of GSH and concomitant increase in malondialdehyde level in the liver, heart and brain of diabetic untreated rats in this study is in supports of previous studies $(38,39)$.

\section{Conclusion}

We concluded that in addition to the numerous medicinal benefits attributed to oil from Eucalptus globulus leaf, its methanolic leaf extract (EGLEX) possesses antidiabetic property, improves biomarkers of therapeutic response and diabetic disease progression, and has potential to prevent diabetic complications.

\section{Conflict of Interest:}

Authors declare no conflict of interest.

\section{Acknowledgements:}

We acknowledged the authors whose publications were used in the preparation of this manuscript.

\section{References}

1. Cerasoli S, Caldeira MC, Pereira JS, Caudullo G, de Rigo D. Eucalyptus globulus and other eucalypts in Europe: distribution, habitat, usage and threats. In San-Miguel-Ayanz J, de Rigo D, Caudullo G, Houston Durrant T, Mauri A (Eds.) European Atlas of Forest Tree Species, Publ. Off. EU, Luxembourg 2016; pp. 90-91.

2. Damjanovic-Vratnica B, Dakov T, Sukovic D, Damjanovic J. Antimicrobial effect of essential oil isolated from Eucalyptus globulus Labill. from Montenegro. Czech J Food Sci 2011; 29: 277-84.

3. Akolade JO, Olajide OO, Afolayan MO, Abayomi, T. Chemical composition, antioxidant and cytotoxic effects of Eucalyptus globulus grown in north-central Nigeria. J. Nat. Prod. Plant Resour. 2012; 2 (1): 1-8.

4. Hayat U, Jilani MI, Rehman R, Nadeem R. A Review on Eucalyptus globulus: A New Perspective in Therapeutics. International Journal of Chemical and Biochemical Sciences 2015; 8: 85-91.

5. Kesharwani V, Gupta S, Kushwaha N, Kesharwani R, Patel DKM. A review on therapeutics application of eucalyptus oil. International Journal of Herbal Medicine 2018; 6(6): 110-115

6. American Diabetes Association. Diagnosis and Classification of Diabetes Mellitus. Diabetes Care 2005; 28: 37- 42.

7. Simo-Servat O, Simo R., and Hernandez R. Circulating biomarkers of diabetic retinopathy: An overview based on physiopathology. J Diabetes Res, 2016 5263798.

8. Dik Y. How is NLR and PLR affected in Type 2 diabetes mellitus compared to healthy population? Medical Science and Discovery 2020; 7(2):405-8

9. Ajilore BS, Olorunnisola OS, Owoade AO. Tetracarpidium conophorum Seed Extract improves Markers of Diabetic Disease Progression in Streptozotocininduced Diabetic Rats. Phytomedicine-Plus 2021; 1(4): 10.1016/j.phyplu.2021. 100091

10. National Research Council (US) Committee for the Update of the Guide for the Care and Use of Laboratory Animals. Guide for the Care and Use of Laboratory Animals. 8th edition. Washington (DC): National Academies Press (US) 2011. https://www.ncbi.nlm.nih.gov/books/NBK54050/ doi: $10.17226 / 12910$

11. Ajilore BS, Adesokan AA. Antidiabetic effects of Tetracarpidium conophorum seed on biomarkers of diabetes-induced nephropathy in rats. Asian Pac J Trop Biomed 2018; 8: 593-7.

12. Nathan DM, Singer DE, Hurxthal K, Goodson JD. The clinical information value of the glycosylated hemoglobin assay. New Eng J. Med 1984; 310: 341 -346 .

13. Ramnik S. Medical Laboratory Technology (Methods and Interpretation). District Laboratory Practice (5th ed.). JAYPEE 2006.
14. Tonk DB. The estimation of cholesterol in serum: A classification and critical Review of methods. Clinical Biochemistry 1967; 1:12-29.

15. Assmanna G, Jabs HU, Kohnert U, Nolte W, Schriewera H. LDL-cholesterol Determination in blood serum following precipitation of LDL with polyvinylSulfate. Clinica Chimica Acta 1984; 40(1): 77-83.

16. Fossati P, Prencipe L. Serum triglyceride determined colorimetrically with an Enzyme that produce hydrogen peroxide. Clin Chim ActaI 1982; 28: 2077-2080.

17. Ottolenghi, A. Interaction of ascorbic acid and mitochondria lipids. Arch Biochem Biophys 1959; 79: 355-363.

18. Sapakal VD, Shikalgar TS, Ghadge RV, Adnaik RS, Naikwade NS, Magdum CS. In vivo screening of antioxidant profile: a review.J. Herbal Med. Toxicol 2008; 2(2): 1-8.

19. McCord JM, Fridovich I. Superoxide dismutase. An enzymic function for erythrocuprein (hemocuprein). J. Biol. Chem 1969; 244(22): 6049-6055.

20. Gornal AG, Bardawill CJ, David MM. Determination of serum proteins by means of the biuret reaction. J. Biol. Chem 1949; 177(2): 751-66.

21. Ajilore BS, Oluwadairo TO, Olorunnisola OS, Fadahunsi OS, Adegbola PI. GC-MS Analysis, Toxicological and Oral Glucose Tolerance Assessments of Methanolic Leaf Extract of Eucalyptus Globulus. Future Journal of Pharmaceutical Sciences 2021 (in-press).

22. Simo-Servat O, Simo R, Hernandez R. Circulating biomarkers of diabetic retinopathy: An overview based on physiopathology. J Diabetes Res 2016; 5263798.

23. Saravanan P, Mohan SG, Rani J, Shanmuga SP (2014) GC-MS analysis of phytochemical constituents in ethanolic bark extract of ficus religiosa linn. International Journal of Pharmacy and Pharmceutical Sciences 6:457-60.

24. Howarth FC, Jacobson M, Shafiullah M, Adeghate E. Long term effects of streptozotocin-induced diabetes on the electrocardiogram, physical activity and body temperature in rats. Experimental Physiology 2005; 90: 6.

25. Ajilore BS, Olorunnisola OS, Owoade OA. Tetracarpidium conophorum (African Walnut) Seed Protects against Diabetes-induced Liver Damage in Rats treated with Streptozotocin. Romanian Journal of Diabetes, Nutrition and Metabolic Diseases 2020; 27(2): 135-145.

26. Shiva RKC. Diabetes mellitus and Glycosylated Hemoglobin A1c. Nepalese Medical Journal 2018; 1: 112-117.

27. Menart-Houtermans B, Rutter R, Nowotny B, Rosenbauer J, Koliaki, C, Kahl S. et al. Leukocyte Profiles differ between Type 1 and Type 2 Diabetes and are associated with metabolic phenotypes: Results from the German Diabetes Study (GDS). Diabetes Care 2014; 37: 2326-2333.

28. Mertoglu C, Gunay M. Neutrophil-Lymphocyte Ratio and Platelet-Lymphocyte Ratio as Useful Predictive Markers of Prediabetes and Diabetes Mellitus. Diabetes and Metabolic Syndrome: Clinical Research and Reviews 2016; S1871-4021(16)30258-2.

29. Zuberi BF, Akhtar N, Afsar S. Comparison of mean platelet volume in patients with diabetes mellitus, impaired fasting glucose and non-diabetic subjects. Singapore Med J 2008; 49:114116.

30. Demirtunc R, Duman D, Basar M, Bilgi M, Teomete M, Garip T. The relationship between glycemic control and platelet activity in type 2 diabetes mellitus. J Diabetes Complications 2009; 23:8994.

31. Wang J, Chen Z, Yang K, Yang H, Tao W, Li Y, et al. Association between neutrophil-to-lymphocyte ratio, platelet-to-lymphocyte ratio, and diabetic retinopathy among diabetic patients without a related family history. Diabe tology and Metabolic Syndrome 2020; 12: 55.

32. Chen W, Chen K, Xu Z, Hu Y, Liu Y, Hu X, et al. Neutrophil-to-Lymphocyte Ratio and Platelet-to-Lymphocyte Ratio Predict Mortality in Patients with Diabetic Foot Ulcers Undergoing Amputations. Dove Press: Diabetes, Metabolic Syndrome and Obesity: Targets and Therapy 2021; 14: 821829.

33. Lemieux J, Lamarche B, Couillard C, Pascot A, Cantin B, Bergeron J. Total cholesterol / HDL cholesterol ratio vs LDL cholesterol/ HDL cholesterol ratio $\mathrm{s}$ indices of ischemic heart disease risk in men: The Quebec cardiovascular study. Arch Intern Med 2001; 161(22): 2685-2692.

34. Khan HA, Sobki SH, Khan SA. Association between glycaemic control and serum lipids profile in type 2 diabetic patients: $\mathrm{HbA1c}$ predicts dyslipidaemia. Clin Exp Med 2007; 7:2429.

35. Faulkner MS, Chao WH, Kamth SK. Total homocysteine, diet and lipid profiles in type 1 and type 2 diabetic and non-diabetic adolescents. J Cardio vasc Nurs 2006; 21: 47-55.

36. Yan Z, Liu Y, Huang H. Association of glycosylated hemoglobin level with lipid ratio and individual lipids in type 2 diabetic patients. Asian Pacific Journal of Tropical Medicine 2012; 469-471.

37. Leung TM, Nieto N. CYP2E1 and oxidant stress in alcoholic and non-alcoholic fatty liver disease. J Hepatol 2013; 58: 3958.

38. Yagmur E, Tacke F, Weiss C, Lahme B, Manns MP, Keifer P, et al. Elevation of Nepsilon-(carboxymethyl) lysine-modified advanced glycation end products in chronic liver disease is an indicator of liver cirrhosis. Clin Biochem 2006; 39: 39-45.

39. Ullah A, Khan A, Khan I. Diabetes mellitus and oxidative stress A concise review. Saudi Pharmaceutical Journal 2015; DOI: 10.1016/j.jsps.2015.03.013 